viz., that "suggestion" is at the bottom of all hypnotic phenomena.

Dr. Moll in his third chapter gives the Symptomatology of Hypnotism with great minuteness, but we cannot follow him into all the interesting physiological and psychological questions which he raises. Among the most striking features of hypnosis are the subjection of the voluntary muscles to external suggestion, the loss of the power of voluntary motion, rjgidity of the whole body on the one hand, or on the other that peculiar condition to which the term "flexibilitas cerea" has been applied, various contractures ; the phenomena of imitative speech (ecbolatic), the patient repeating what is said to him like a phonograph; sense delusions of various kinds, hypnotics being made to drink ink for wine, to eat onions for pears, to smell ammonia for eau de Cologne, \&c. The senses of touch and taste are said to be those most easily influenced. The mucous mem. branes can be made anæsthetic by suggestion in bypnosis to such an extent that the fumes of ammonia in the nose and tickling of the throat are not felt ; even the conjunctiva can be touched without producing the corresponding reflex. The muscular sense can also be inhibited in hypnotism, the patient resembling a sufferer from locomotor ataxia. Complete analgesia is exceedingly rare in hypnotism according to $\mathrm{Dr}$. Moll, although it has often been regarded as common.

The influence of hypnotic suggestion upon the various physiological functions is a very curious subject, and some of the alleged facts are novel and startling. Krafft-Ebing claim to be able to produce any temperature he pleases in his patients by suggestion. Heidenhain and Preyer claim to have succeeded in controlling the secretion of urine. The perspiration and the saliva are also said to be under the influence of suggestion. Local reddening of the skin, slowing of the action of the heart, \&c., have been said to be similarly affected. Startling as are such assertions, it can hardly be said that they present any $a$ priori impossibility. It is quite impossible to assign any limit to the influence of mind upon body, which is probably much more potentand far-reaching than we are usually prepared to admit. Even more startling statements follow. We are informed that under the influence of hypnotic suggestion blisters can be made to rise upon a patient if he can be made to believe that a blister has been applied to him. Marks like burns are said to have been produced by pressing such objects as a snuff-box or a pair of scissors to the skin, the patient being told that the skin was being burned. Various bleedings are said to be capable of being produced by suggestion. Wheals, redness, and swellings are said to have followed the slightest pricks to the skin when the patient had been led to expect them.

Notes on the Examination of the Sputum, Vomit, Freces, and Urine. By SIDNEY Coupland, M.D., F.R.C.P. London : H. K. Lewis.

IT has been aptly remarked that time is short and practical medicine is long, only a very small portion of the art being acquired even in a lifetime. It is all the more essential therefore that "Notes" purporting to give informa. ticn on that subject should be at once for the most part com. prehensive, concise, accurate, and arranged in such a form as will aid the student to retain them in his memory. These characteristics will be found in the "Notes" contained in the present little volume, for which the author modestly "lays no claim to any originality either in the subject matter or in the form in which it is presented." We think, however, that the work shows great originality, and more particularly in avoiding the practice so usual in students' note-books of condensing the print and not the matter. The work deals with every thing connected with the sputum, vomit, fæces, and arine which a student or practitioner ought to know, and will form an excellent book of directions for those who are about to be examined on the subject of practical medicine.

\section{ROYAL COMMISSION ON TUBERCULOSIS}

\section{To the Editors of THE LANCET.}

7 , Whitehall-place, London, S.W., March 16th, 1891.

Sins,-Will you be good enough to find a place in your columns for the enclosed copies of letters and question papers which have been forwarded at the request of this Commission by the Local Government Board to the medicas officers of health?

I am, Sirs, your obedient servant, LEOPOLD HUDSON, Secretary.

7, Whitehall-place, London, S.W., February, 1891

SIR,-I am requested by the Commission to state that they will feel very much indebted if the President of the Local Government Board will cause the enclosed question papers to be forwarded to the medical officers of health of the United Kingdom, together with a note commending them to their consideration.

The Commission was appointed on the 21st July, 1890, " to inquire and report what is the effect, if any, of food derived from tuberculous animals on human health; and, if prejudicial, what are the circumstances and conditions with regard to the tuberculosis in the animal which produce. that effect upon man."

The Commission have pursued this investigation up to a certain point and are engaging in certain experiments. They also desire to ascertain by inquiry through the medical officers of health of the United Kingdom whether any ex. perience has been obtained by local medical observers that may throw light on the subject referred to the Commission.

Any experiences of the medical officers will be particularly valued, if they will be good enough to reply to the questions on the enclosed form. The Commission will also be obliged if they will kindly forward a copy of these questions to any practitioner in their neighbourhood who they think may' be able to furnish information of the kind needed. I am, Sir, your obedient servant, LEOPOLD HUdSON, Secretary. To the Secretary, the Local Government Board.

Local Government Board, Whitehall, S.W., March 16th, 1891. SIR,-I am directed by the Local Government Board to forward to you the accompanying copy of a letter from the Royal Commissioners on Tuberculosis, expressing their desire to enlist the coöperation of medical officers of health in collecting information on the particular points specified in the memorandum of which copies are also enclosed; and $I$ am to state that the Board will be obliged by your affording any assistance in your power to the Royal Commissioners in the important inquiry which they have undertaken.

Information on the subject, furnished by yourself or by any medical practitioner in whose hands you may think it useful to place a copy of the memorandum, should be com. municated to the Secretary of the Commission, 7, Whitehall-place, London, S.W.

I am, Sir, your obedient servant,

To Medical Officer of Health. HuGH OWEN, Secretary.

7, whitehall-place, London, S.W.

Medical practitioners are invited to record for the in formation of the Commission any observations that they may have made on the apparent communication of tubercle from animal to man or from man to animal.

Information is asked for under the following heads :-

1.-A history, with particulars, of any case of tuberculosis in man which has appeared to the observer to be caused by the use of tuberculous food (meat or milk) or by attendance on tuberculous animals.

2.-A history, with particulars, of any case of tuberculous infection of animals which has appeared to the observer to have been contracted from human subjects suffering from tuberculosis.

3.-A history, with particulars, of habitual use of animal food believed by the observer to be tuberculous in cases where individuals or communities have kept free from tu berculous disease.

Replies to this inquiry will be received by Mr. Leopold Hudson, secretary of the Commission, at the above address. February, 1891. 


\section{THE LANCET.}

\section{LONDON: SATURDAY, MARCH 28, 1891.}

THE Registers of the profession have made their appearance a little earlier than usual. Last year they were not issued till April 17th. This year we received them on March 18th. In 1887 they were as late as April 29th. We must be thankful for the improvenent in respect of time. But there is room for more. It is probably less the fault of the registrars than of the publishers; but it is clearly somebody's fault that public documents of great importance do not appear till nearly a quarter of the year is over. There are great lessons to the profession to be derived from a study of these Registers, which we may briefly indicate. First, they constitute the great and official roll of the profession. There are other compilations of great interest and with a value of their own, but for official and legal purposes, unless a practitioner finds his name here he is a private and non-medical person. Our first inquiry is as to the numbers of the profession. In the Medical Register itself there is no falling off. Perhaps when we come to the Register of Medical Students we may see indications of a recognition of the fact that the profession is overstocked and that young men are perceiving the fact. But in the Medical Register of the 31 st December, 1890 , there were no less than 29,163 names. This exceeds the number registered on the same day in the previous year by no less than 815 !-a startling addition to an already excessive quantity. When we come to inquire into the details of the explanation it may seem a little less startling. But still the fact remains that 29,163 are on the Register for this year, against 28,318 in the previous year. They are not all pure additions-that is, names added for the first time to the Register. Of such fresh names there is a little falling off in the last year. In the three divisions of the kingdom-England, Scotland, and Ireland,-there were respectively 637,462 , and 167 added by registration, or 1266 in all, as against 657,444, and 204, or a total of 1305 in the previous year-a difference of diminution of thirty-nine new registrations. There is a clause (14) in the Medical Act which empowers the Registrar, after certain fruitless inquiries, to remove names; and in some years huadreds of names are removed, in others hundreds are restored under this clause. In 1889 no less than 407 were so removed; last year the number was only 82. Practitioners so removed often apply for restoration, and in last year 105 names were restored, against 82 in the previous year. Clause 14 gives oscillation to the numbers on the Register, which must be considered in estimating the real additions by registration for the first time. We have seen these were less than in the year before by 39 , and less than the average of the last five years by 78. So the additions, as compared with the previous year, are not quite so alarming, when they come to be analysed, as at first sight they appear to be. But as a matter of fact, there is a greater number of names on the Register for 1891 than there had been in any previous year, and doubtless represent an excess of the actual wants of the empire.

There are three or four ways by which men disappear from this roll of the profession which demand a few sentences. Happily those erased for evil behaviour only average two a year. Hundreds, as we have said, may be removed by carelessness in intimating changes in address. Some men cease to practise. It will surprise men of more lucrative and leisurely callings to learn that seven practitioners a year on an average so withdraw from the Medical Register. There remain the removals by death. And here we find the Registrar's figures most satisfactory and most unsatisfactory. Satisfactory as showing so healthy a state of the members of the profession; unsatisfactory as showing that the Registrar and Dr. OGLE are at serious variance as to the mortality of medical men. The removals from the Register by death have been only 467, which for the numbers in the previous Register $(28,348)$ give a mortality of something over 15 per 1000 . Dr. OGLE, a few years ago, gave the mortality of medical men as 25 in the 1000 . We can scarcely doubt that the actual mortality of the profession exceeds 467 , in spite of the Registrar's great pains to be accurate; but we are disposed to believe that it is not nearly so high as Dr. OGLE's statistics seemed to prove.

A novelty in the Medical Register is the Colonial Register. But our readers need not be unduly alarmed. It contains only two names-viz, those of two graduates of the University of Melbourne, one resident in Melbourne and one in London. Coming to the Register of Medical Students, it contains much material of interest, but we have only space to notice the supply of medical students, and the principal sources whence it comes. We find a falling off in each division. In England there were 974 registrations, in Scotland 613, in Ireland 229, in all 1846; as against 1039,702 , and 286 , in all 2027 , in the previous year. The number is less than in any of the previous twelve years, except 1883, when it was 1783 . We must not too hastily conclude that the rush into the profession of late years has been really stayed. The commencement of medical study may either be at a medical school, or a hospital or infirmary, or by pupilage with a medical practitioner. It is interesting to note with regard to this latter method that it is followed by 140 of our new students. Cambridge, in England, has the largest number of registered students, 104. Edinburgh, in Scotland, has 244, the largest number of any school. In Ireland the largest number is in Queen's College, Cork.

The Dentists' Register contains 4802 names of dentists who hold diplomas from bodies in the United Kingdom, and fifteen from foreign sources, of which six are from Harvard University and nine from Michigan.

THE next meeting of Convocation, on May 12th-wher the Draft Charter, prepared on the basis of the latest revised scheme, will be laid before the members for their acceptance or rejection-will be one of the most important in the history of the University of London. The Draft Charter, as well 